\title{
Designing Video Stories Around the Lived Experience of Severe Mental IIIness
}

\author{
Mahsa Honary \\ School of Computing and \\ Communication \\ Lancaster University \\ Lancaster, United Kingdom \\ m.honary@lancaster.ac.uk
}

\author{
Roisin McNaney \\ School of Computing and \\ Communication \\ Lancaster University \\ Lancaster, United Kingdom \\ r.mcnaney@lancaster.ac.uk
}

\author{
Fiona Lobban \\ Spectrum Centre for Mental \\ Health Research \\ Lancaster University \\ Lancaster, United Kingdom \\ f.lobban@lancaster.ac.uk
}

\begin{abstract}
Caregivers of people experiencing severe mental illness (SMI) report a multitude of psychosocial impacts, including feelings of loneliness and isolation, distress, societal stigma and prejudice around mental health. We describe the design of a series of video stories, performed by actors, which were based on the lived experiences of caregivers and people with SMI. We conducted a series of in-depth qualitative interviews with 11 participants, which formed the basis for the video content. We then worked alongside two caregivers (as advisors), at each stage of the production process, to develop a set of 45 video stories, using personas in our process. Through a discussion of our creative process, we offer a set of considerations for future researchers wishing to develop relatable and empathic digital content for online information provision and support tools. In addition, we offer a set of reflections around the complex ethical challenges underpinning this design space.
\end{abstract}

\section{Author Keywords}

Severe mental illness; User-centered design; Video stories; Experience sharing; Digital stories

\section{ACM Classification Keywords}

H.5.m. Information interfaces and presentation (e.g., HCI): Miscellaneous.

\section{INTRODUCTION}

Severe Mental Illness (SMI) is an umbrella term encompassing a wide range of mental health conditions, including major depression, personality disorder, bipolar disorder and psychosis. Caring for someone with SMI can be a lonely role; caregivers are often left unassisted to cope with challenging situations resulting from the SMI, and they can

Permission to make digital or hard copies of all or part of this work for personal or classroom use is granted without fee provided that copies are not made or distributed for profit or commercial advantage and that copies bear this notice and the full citation on the first page. Copyrights for components of this work owned by others than ACM must be honored. Abstracting with credit is permitted. To copy otherwise, or republish, to post on servers or to redistribute to lists, requires prior specific permission and/or a fee.

Request permissions from Permissions@acm.org.

NordiCHI'18, September 29-October 3, 2018, Oslo, Norway (c) 2018

Association for Computing Machinery.

ACM ISBN 978-1-4503-6437-9/18/09 ..\$15.00

https://doi.org/10.1145/3240167.3240188 find it difficult to discuss their issues and feelings with others due to fears of societal stigma and personal prejudices surround mental health. This can leave caregivers feeling helpless and isolated, with the view that they are the only ones facing many of these difficult experiences [29]. Improving caregiver capacity to cope better with the stressors linked to caregiving has threefold effect $[12,38$, 45], by enhancing caregiver wellbeing, having a positive impact on recovery of the patient, especially to reduce relapse, and by reducing burden on health and social care services. This can be done by providing emotional and informational support and family intervention to caregivers of people with SMI. However, due to staff and caregivers' limited time, and the resources required to provide formal support, it is often the case that caregivers' own mental health needs are not addressed [50].

There is a small, but emerging, HCI literature within the space of digital support for people with SMI [21-23], however work which has focused predominantly on supporting the caregiver is limited [24, 96]. Given the acknowledged feelings of isolation that caregivers can face [29], there is a need for tools which can help caregivers feel that they are not alone in their experiences. The therapeutic benefit of sharing personal stories for people with traumatic lived-experiences has been recognised in the literature [33, 67]. Moreover, it has been acknowledged that sharing visual stories is a powerful way of connecting and empowering people who have similar lived-experiences $[13,18]$. Much work focusing on experience sharing within other chronic health conditions such as cancer or diabetes has looked at the use of video as a way to achieve an emotional connectedness and mutual empathy between members of a health community [48]. However, this work mainly focuses on user generated content $[37,48]$, which can be challenging in the context of discussing sensitive topics i.e. mental health, in particular from a caregivers perspective.

In this paper we describe a 6 month long design-led study conducted with 11 participants, which formed part of a larger clinical project [50]. Our work aimed to create a set of videobased stories (portrayed by actors to maintain the privacy of participants), to feed into an online toolkit to support 
caregivers of people with psychosis or bipolar disorder. A full discussion of this toolkit extends the scope of this paper but, in summary, Relatives Education And Coping Toolkit (REACT) is a modular intervention for caregivers of people with bipolar disorder and psychosis. The modules cover topics such as understanding mental health services, managing stress and treatment options, among others [50].

Our contribution to the HCI community is threefold. First, we offer an empathic understanding of the lived-experiences of people experiencing SMI and their caregivers; second, we provide a framework for designing relatable, accessible, and privacy sensitive digital content for online tools to support those caring for people with SMI; finally, we offer reflections around the complex ethical challenges underpinning digital tool creation for mental health, to inform future designers wishing to work within this space.

\section{Living with severe mental illness}

Severe mental illness, suffered for 12 months or more, is thought to affect approximately $4-7 \%$ of the global population [44]. Bipolar Disorder (BD) is characterised by recurrent periods of extreme mood including depression, mania and mixed affective states [27]. Those affected are prone to making impulsive, precarious decisions (e.g. spending money or impulsive sexual behaviours) [59]. Those suffering from psychosis can experience presence of symptoms including 1) delusion believing things that are generally accepted to be untrue by other people; 2) conceptual disorganisation not being able to think straight and so sounding very confused; 3 ) hallucination (auditory or visual) experiencing things that aren't really happening; 4) cognitive deficits; and 5) affective symptoms such as depression and agitation [2]. Coping with and managing these symptoms on a daily basis can be very challenging for, not only the individual experiencing them, but also the family and friends who support them. Caregivers of people with SMI are the predominant point of care and support for their loved one, often without any formal training and support $[1,8]$. This, often full time, caring role is reported to be overwhelming and stressful, as well as having a negative impact on family relationships, employment, finances and individual's quality of life [19]. This caring role can cause distress and burden on caregivers [3, 52, 53, 70, 87, 97]. Impacting factors include patient behaviour, changes in caregiver and patient functioning, social support networks, caregivers' coping strategy, family functioning, perceived stigma and caregivers' mental wellbeing $[16,77]$. In addition to the burden of care, SMI can bring shame, embarrassment, feelings of guilt and self-blame to the caregiver [2].

In the existing HCI literature focusing on SMI, little work has explored the caregivers' role [91]. Most of the undertaken studies have focused on providing digital support and education for the patients $[4,46,55]$. While web-based interventions are increasingly being offered to caregivers of other chronic health conditions [68, 72, 79, 84, 94], less progress has been made in mental health. However, the importance of supporting caregivers across various health domains, including mental health, has been recognised [20, $22,64,78]$. Research has shown that informal and regular caregivers of those with SMI benefit from education and support $[11,49,69,99]$. While there is a need to provide face to face support to caregivers, support can be facilitated through cost effective digital platforms as they offer accessibility, inclusivity and anonymity which can be appreciated in a stigmatised mental health context $[31,54$, $56]$.

\section{The value of online support}

For people living with a health condition, several motivations surrounding participation in online health communities have been noted within the literature. First, when experiencing a chronic health condition, there is a desire to seek social support from others who have similar personal experiences, and can thus offer empathy and compassion in ways others cannot [98]. In addition, health communities focused on specific conditions can offer a stigma-free space, comprised of people representing a diversity of experiences and advice, all with their own links to available information and resources [47]. Access to these online resources has also been found to correlate with better medical knowledge, which can facilitate patient-clinician interactions and increase confidence around decisionmaking [81]. Pang et al. [66] and Vines et al. [92] describe the issues faced by people attempting to learn about health related topics online, such as not having the available vocabulary to search with, and concerns around how they can relate these to their own circumstances. Increasingly people with any known health condition can search online resources to acquire information and support [43].

Over the past decade, as access to multiple online digital media platforms has grown, we are seeing an emergence in patient-generated content capturing the lived-experiences of people with health conditions. This has been shown to influence patients with health-related decision-making [26, 83, 100]. The literature shows that people tend to draw on online resources that are generated by those with similar experiences to themselves [82] and that people are more likely to trust the advice coming from 'experts by experience' with similar social identities to themselves [6, 80]. Different mediums exist for incorporating usergenerated content into online resources. Patients or caregivers often use social media, discussion forums, blogs or video hosting sites to share their personal lived-experience stories [62, 65].

Video as a means to establish emotional connection Several studies have used video medium (e.g. vlogs, web videos, video documentaries and YouTube videos) as an educational tool to provide support and information for various health conditions $[25,30,40,48,63]$. The medium of video facilitates disclosure of more personal and emotional information [7]. A significant body of research has investigated how health video blogs (vlogs) [60] can have 
positive impact, both informationally and emotionally, on viewers effected by a health condition [30, 42, 63, 85].

Sharing stories via video can facilitate an emotional connection and promote empathy and relatedness towards 'expert by experience' stories [58, 92]. In addition, creating video stories that can be implemented within digital health interventions can instigate increased engagement with digital tools. However, when this is carried out by a caregiver (discussing another person with SMI) this can present new ethical and pragmatic shortcomings, particularly when considering the use of online health tools which are created and implemented in a clinical context. For example, videobased experience sharing which originates from patients is often delivered by people who are at a good enough point in their recovery to discuss their health condition openly online and share their identity. This can be challenging in stigmatised health domains such as mental health, especially in the context of experience-sharing as a caregiver, which can lead to issues around ownerships over the story being shared. This raises the importance of exploring new ways of creating privacy sensitive stories.

\section{OUR STUDY}

In the following sections we detail our study, which aimed to explore the production of a set of relatable, video-based stories detailing lived experiences of SMI, whilst maintaining the privacy of patients. The video creation process involved three phases: 1) a series of scoping interviews, to understand the experiences of SMI from the perspectives of different types of caregivers and patients; 2) the creation of a set of personas which could be used to support storyline extraction from the data; and 3) rehearsal and recording with actors, with guidance from several of the caregivers who shared their stories.

\section{Participants}

A total of 11 participants (6 female, 8 caregivers,) were recruited to take part in the study. Our purposive sample included both caregivers of, and people suffering from, bipolar disorder or psychosis, to ensure that a range of insights surrounding experiences of SMI were portrayed within the story sharing videos. Potential participants were contacted via an advertisement, circulated through the social media accounts, participant database and patient advisory group of the Spectrum Center for mental health research at Lancaster University. The participants were offered a $£ 20$ Amazon voucher in appreciation of their time and involvement. Participants represented a diverse set of experiences. Of the caregivers, two provided care to a spouse, three to a sibling and two to a child (over 18). One participant both had experience of providing care to a parent with SMI and was a patient themselves. The final three participants were patients.

\section{Who owns the story? Production decision}

In the early stages of our study, the production method was debated across the team including our caregiver advisors. Our intention was to produce videos that best resonate those affected by the SMI population. To achieve this, we consulted the use of interview recordings. Our advisors raised concerns on anonymity, particularly underlining the issue of caregivers discussing their loved one's condition in their videos, which could lead into identifying the person with SMI. They highlighted that even if the video is about the caregivers' feelings it can still give away information about the patient which made them feel uncomfortable about sharing this content.

We then considered getting consent from all parties affected by the video production [71] e.g. caregivers and their family member whom they will be discussing in the videos. However, the possibility of the person with SMI not being clinically fit to consent was raised and the need for clinical assessment prior to consent was identified. In addition, it is possible that even when the caregivers and their loved ones are happy and clinically fit to consent, they may change their decision at a later stage. This might not always be possible to implement as, due to the nature of digital platforms, videos can be watched by many viewers. Despite the attempt to fight against the stigma associated with mental health, being identified as someone suffering from mental illness can have a negative impact on the person's personal, social and professional life. We considered pixelating the videos or recording only the arm movements. However, we felt that these techniques may minimise the emotional connection we wished to establish with our audience.

After thorough consideration, we reached the decision to interview the caregivers and their loved ones capturing their lived-experience stories and use professional actors to retell the stories in order to protect the identity of the participants.

\section{Scoping interviews}

We conducted one-to-one semi structured interviews which focused on sharing experiences of living with SMI. Interviews were conducted face to face at Lancaster University, where possible, or remotely via WebEx. Some participants were related and requested to be interviewed separately; only one couple (a mother and daughter) preferred to attend a joint interview and share their experiences together. Participants were prompted to share their stories on: 1) how SMI was affecting their personal, social and professional life; 2) maintaining family relationships; 3) their experiences of living with SMI; 4) their coping strategies; and 5) any useful information they wished to share with newly-diagnosed families. The questions were tailored to the mental health condition participants were dealing with i.e. bipolar disorder or psychosis. Interviews were video recorded for later analysis by the research team. Participants also gave consent for this video material to be watched by the actors (in the presence of the research team) who would portray the final video stories.

\section{Development of Personas}

The researcher who carried out the interviews and was familiar with all interviewees, then created 6 personas based 


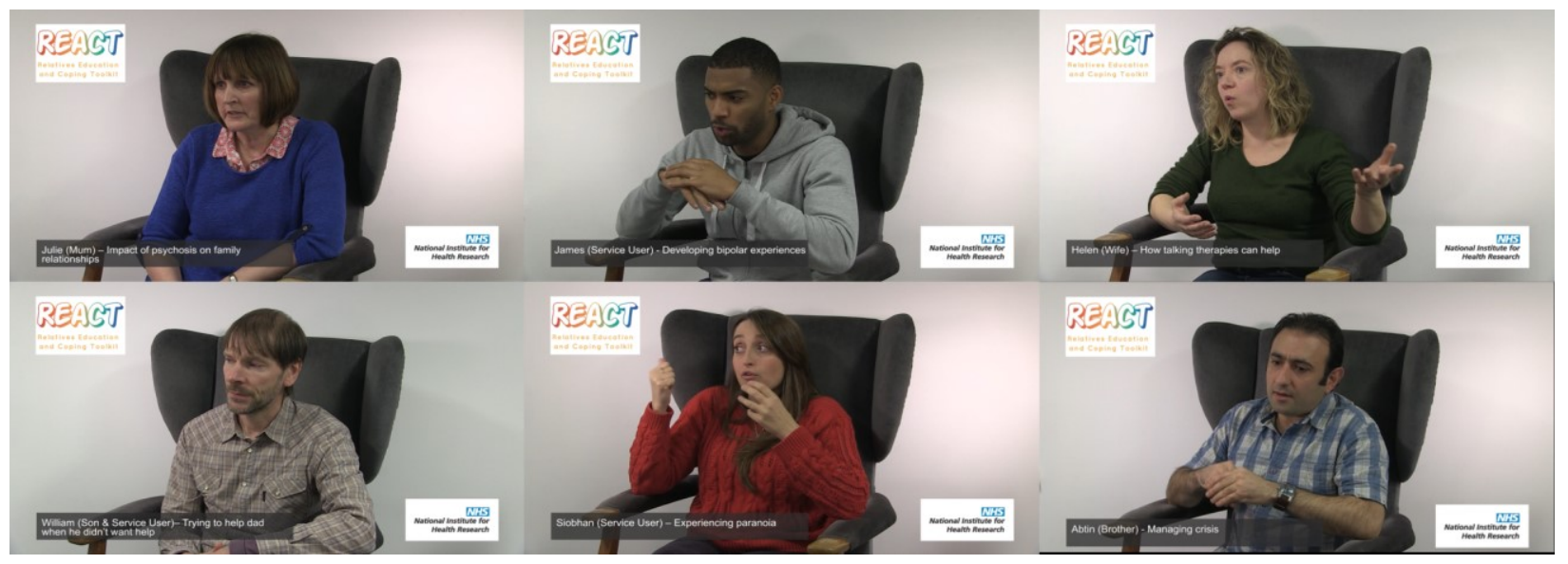

Figure 1: Screenshots from videos played by actors

on the characteristics and shared experiences of the participants who represented each persona category (i.e. parent, child, spouse, sibling). For example, when we interviewed two participants who provided care to their husbands we combined the characteristics of both interviewees and created a new persona for a wife character. The created personas were further discussed and modified with another researcher to ensure they were representative of the data as well as the wide range of family relations involved in care.

Personas can be used as a way to create relatable content and avoid 'characterless' and 'lifeless' scenarios [5, 75]. In addition, they are a useful tool for understanding and communicating information about our target audience and ensuring the consistency of vision across the analysis team $[14,28,41,73,74]$. Utilizing personas in our study had three advantages: i) helped us make assumptions about our target audience based on different relationships and experiences and therefore extract more meaningful data from the interviews; ii) enabled efficient communication across the analysis team about aims and process of our analysis; and iii) helped actors in phase 3 to intuit a background of the character on whom they would portray. Personas helped us to ask questions about the needs of our target audience (e.g. what would spouses want to know about their legal rights as first point of contact? What would siblings want to know about managing challenges whilst growing up with a sibling suffering from SMI?).

In the persona descriptions, we focused on interviewees' experiences around how their family was first affected by SMI and drew on their routine caregiver duties. The following 6 personas were created based on the combined experiences of the interviewees. The names used are pseudonyms:

Helen My partner of 10 years has schizophrenia. He's been displaying symptoms for about seven years now but was only diagnosed 3 years ago. We've got two children and he first became ill when I was pregnant with our first son. We saw some symptoms early on, but it was quite difficult to get him to go to a doctor. We have a very good relationship so I am now actually part of his care plan.

$\underline{\text { Abtin }}$ My older sister was diagnosed with psychosis over 10 years ago. I gradually became involved with her care because other members of the family just didn't have the time, understanding or capability. I had to fight for my legal right as her caregiver, and I never gave up until this happened now I am involved in all her meetings and decisions.

Siobhan I have had depression for about 14 years, and then about a year ago I was diagnosed with psychosis as well. I've had quite a lot of traumatic life experiences so I think my psychotic condition is the result of having experienced these events.

$\underline{\text { Julie }}$ As far as I know, my son was diagnosed with psychosis. He never wanted me to go into his meetings in hospital, as if there was a big dark secret he didn't want me to find out about. He went to great lengths to stop me finding things out, and wanted me to be distant from his condition. My daughter tried to go to the meetings instead, but he didn't like that so it caused a rift between them and he didn't speak to her for several months. He decided to keep his meetings and condition private.

James I became ill recently after travelling - I came back on a plane thinking I'm some sort of extra-ordinary amazing person who doesn't need to sleep and was talking absolutely non-stop. It was very confusing for everyone, especially my parents, who couldn't even begin to understand what was going on. It must have been really difficult and stressful for them, because they ended up calling the GP which resulted in me being detained in a psychiatric hospital. I was very angry with my parents for a very long time, but they have been a huge support for me, have always put up with me and almost put to one side their own emotional needs - I don't know what the future holds yet, but I can't thank them enough for their help so far.

William My dad was diagnosed with depression for as long as I can remember, and then about 10 years ago he was diagnosed with Bipolar Disorder. At the time, he was looking 
after my mum, who had Multiple Sclerosis. I also have Bipolar, I think it can be easy to miss by health professionals - I went to see my GP when I was depressed, but during mania, if it's not extreme, you are quite happy and it sometimes doesn't register as a problem.

We then used the personas as a framework for creating a Q\&A style storyline, which would be portrayed by the actors on screen during our video creation. The storylines were developed by analyzing the interviews, and subsequently representing the shared experiences, of participants who represented each persona category. This is described below.

\section{Data analysis for development of storylines}

Six researchers were tasked with analyzing the raw data (videos transcripts of the interviews) and developing a list of shared experiences which could be given as scripts to the actors. These researchers were all highly experienced in the space of SMI and were all members of the Spectrum Center for mental health research at Lancaster University.

Each researcher was provided with the persona of the character they were assigned to, as well as the video and transcripts of any interviews related to that persona (depending on the number of interviews we had for each family role). They were asked to thematically analyse their transcripts using a framework approach [86], to identify the specific emotions, challenges and experiences that their participants faced. They were then asked to develop a script in a Q\&A style, based on a series of questions that had been provided. Some examples of these questions were: Could you share your experience about a time when you were going through a crises with your relative?; Could you tell me about a time when you used a new approach to deal with a difficult crises with your relative?; Do you think that looking after your relative is having an impact on you? Can you describe how? Do you do anything to look after yourself?; What is your experience of accessing mental health services?; What do you understand about available treatment options?; Could you explain about the things you find positive about your future as a caregiver, and the things that might be more worrying?. The scripts were based on the character persona they had been provided but were grounded in the data that had been collected in the interviews. Scripts were developed in a naturalistic and conversational style, and where possible were drawn from the speaking styles of the participants. Many of the scripts contained direct quotes from the participants which had been then edited to reflect the experience of the persona.

\section{Preparing actors for a relatable performance}

In order to help the actors to understand the lived experiences of people affected by SMI and to become familiar with the characters we took the following steps. First actors were given personas and anonymised created scripts outlining the character they were asked to play. This step was taken to help the actors develop their representation of the characters. The actors were invited to an orientation day at Lancaster University. During the orientation session actors watched the interviews related to their character to help them present the participants to the best of their ability. The session included discussions with the analysis team; watching additional material available online from HealthTalkOnline [62] relevant to mental health; and the opportunity to have a discussion session with two caregivers involved in the project as advisors.

We recorded a series of 45 videos across all 6 of our characters, each under 4 minutes long. The recordings happened in presence of a caregiver advisor who provided feedback on authenticity and relevance. The videos were recorded in an interview format (see figure 1). The actors were given a set of Q\&A material covering the key content of the video scripts for the recording day.

\section{EMPATHY, RELATABILITY AND POSITIVE EMOTION}

A total of three overarching themes emerged from thematically analysing all 11 interviews data. Each of the storylines that were created across all of the characters encompassed these three themes which were drawn out in the experience-centred videos that we created. These themes were empathy, relatability, and positive emotion. Below we present segments of the scripts that the actors used in their final performance, which are a synthesis of the experiences from multiple different people who took part in the original interviews that we conducted as the first stage of our study. We discuss each theme in turn, drawing out shared experiences across all persona categories (e.g. parent, child, sibling, patient). We identify quotes based on the persona's name, which have been previously described above.

\section{Empathy}

All four participants suffering from SMI extensively described what it feels like living with SMI. Understanding feelings and experiences that someone with SMI endures can help caregivers cope better when supporting their own loved one in a similar situation. It can provide caregivers with another perspective to the condition which can promote empathy "I feel like I have a double life-people see the face - is confident or intelligent - but they don't understand that it comes at a price -of trauma and pain" [Siobhan].

Hearing about feelings and experiences of those suffering from SMI can reassure caregivers that their loved one's thoughts and beliefs are true to that person. That they are actually experiencing these 'out of ordinary' situations which they often talk about. They explained how one can go from feeling extremely powerful and wanting to change the world, to being completely isolated and depressed:

"Mania is great, it's the best feeling ever, I love feeling like that, you think you can do anything and you think you can be anything you want to be! You might think you are the son of God because it's such a strange experience, you don't understand what's happening to you and you do feel this real power. In my first mania, I did a lot of flow charts, I started drawing things on large pieces of paper which were meant to be solutions to all the problems in the world." [James] 
Participants highlighted the importance of looking into the situation from patient's perspective:

"Nobody ever suggested to me to think from his point of view. Once we had an incident that, out of the blue, he just got very angry with me, to the point that I had to leave, just to stop the argument with him really, and that's something, that in the beginning I wouldn't have done. I would have just stayed there and argued with him and made things worse and instead I just stayed away until things had calmed down and it turned out (that) what he was actually afraid of was him being taken into hospital again. And I'd never, until that point, thought about how he must have felt when he was going through it, when he was being sectioned or taken away by the police. I'd only ever focused on how bad it had made me feel. It would have made things much easier right from when he was little really if I had thought about it in that way. I learnt that when he was getting really stressed the best thing was to walk away." [Julie].

Caregivers explained how accepting SMI as an illness can improve caregiver's capacity to cope and manage the condition:

"I think at the times when Thomas was really ill and he was making the paranoid accusations and things like that I did just have to remind myself that it's an illness and he doesn't really think that... sometimes when I'm really struggling I just say to myself look if he had a different illness like a physical illness if he had cancer or something you wouldn't get mad at him, you wouldn't think about leaving', you know, and everybody would rally to support him. So it's just the same thing and I think because it affects the way they think and the things they say to you it's really difficult to forget sometimes that it's an illness because it hurts. " [Helen]

\section{Relatedness}

All caregivers shared disturbing and challenging memories of caring for their loved ones. They agreed that hearing how other caregivers have managed a challenging crisis would promote a sense of relatability and belonging to others with similar experiences:

"After her last sort of crisis of when she became very high and then became psychotic, she believed she was the Virgin Mary, she had a fixation on a chap, who had been a friend who she met actually whilst in the hospital at one point who lived in our village and she had escaped from the hospital; she thought he was Jesus Christ and she arrived on his doorstep in this state and health professionals still weren't prepared to do anything at that point until I threatened them with basically bringing a solicitor in and an independent psychiatrist to see whether they have her sectioned because they wouldn't have even sectioned her. "[Abtin]

These experiences are unique to the individual and incredibly overwhelming and stressful for the caregivers. Most caregivers are not trained on how to deal with challenging situations i.e. hallucination or delusion. However, hearing about the techniques others in similar situation have used would help them to learn how to handle the crises better:

"There was a time when he thought he was an ambassador for the UN and he phoned the police asking for help, It's really difficult at that point because they're so far removed from reality that it's really difficult to say to them that what your experiencing is a symptom of an illness, but it's just a case of trying to rationalize it really and to say 'you think that really'. He was hallucinating about an alien flying past the window, so you've got to talk them round and say, what is the probability that there actually is an alien out there? How realistic is it? Have you ever seen an alien before? And just to try and talk them round. It is really challenging to know what the best thing to say is but it's just about trying to stay rational really. " [Helen]

All participants emphasized how caring for someone with SMI can have negative emotional impacts on caregivers. One participant, represented in the character of Abtin, explained that the distress of caring for his sister caused a "nervous breakdown" for him. However, participants learned that they need to find ways to distance themselves when needed:

"In the beginning it was very dramatic and painful. And Ifelt very isolated. I remember when he was first admitted to hospital and we were told by the psychiatrist that he would probably always need secure rehab. We came out of that meeting and went to a café and looked round and just felt like I had nothing in common with the people sitting there having an ordinary life and chatting to each other. It was a very, very lonely place, it's like who do you talk to about it 'cos it is just such a unique experience - I guess. I've had to really tell myself that I need good times and holidays and I've had a lot of support from my family and friends. They make sure that I am OK and they help me not to feel guilty that I go on holidays and my son doesn't." [Julie]

These shared experiences can help caregivers understand that they are not the only one experiencing an overwhelming burden of care.

\section{Positive emotion}

Sharing positive advice and support has constructive impact on caregivers coping strategies. Hearing stories about recovery journeys and how both caregivers and their loved ones learn effective techniques for managing SMI can promote positive caregiving approaches:

"He's very good with communication now, we've been through this for so many years he understands that he's ill and we've identified all the symptoms from the early warning signs to the middle and then, you know, the extreme later symptoms and we've got all those written down in a care plan and Thomas is happy that if it gets to the middle stages I can say to him 'look you're showing these middle stages we're really worried about your health now we need to start getting some care in place and I think he's at a point now where he understands that but that's been years and years in the making really." [Helen] 
All participants with SMI expanded on their strategies for managing their mood and their own unique management strategy. The examples were varied, which exhibits how each person's coping mechanism can be different. This understanding would enable caregivers to support their loved one to identify their own unique coping strategy:

"I think I have to see my friends to calm me down, or see a professional in the mental health team or like isolate myself, otherwise I will just talk to myself or I might just get aggressive or anxious and cry because it's quite scary, so I stay at home and I have to stay away from it all, the crowds and all the noises because it's too much for my head. But then sometimes, it can work the opposite 'cos Bipolar is so variable, it's different for everyone. Sometimes when I'm in a very sociable, confident mood, I want the noise; like the loud music, the parties, the pubs, I love it and my head is buzzing and it's like being on drugs 'cos your dopamine is high, your brain is more stimulated. Sometimes that can be dangerous 'cos you're getting too much and then you're getting even higher, it's like when you drink more and you get even higher, you know, it's exactly like that." [James]

Participants had different relationships with their caregivers which was representative of the population and contributes to ecological validity. Some had very close relationships and a supportive network:

"It was very difficult for my parents, up and down in the middle of the night... talking non-stop. They couldn't even begin to understand what was going on and it was really, really difficult for them. I don't know what would have happened if I didn't have a loving family around to support me. Help me to try to live a normal life, to complete my education and think about training, a career and getting on with that." [James]

Whereas some preferred to be a closed book about their mental health and engage with their family and friends in normal life activities:

"It's kind of like you don't want to go in-depth all of the time, even female friends, sometimes you just want to have a bit of fun and talk about general things, like, I don't know, TV programs, or are you going out shopping, or you know all this kind of fun 'what have you done to your hair?' So, I'm learning, sometimes you just need all that little fun stuff and to feel normal, you know, you don't have to go deep. And like I said, a lot of my girlfriends that have been through stuff don't always wanna go deep, they don't wanna make you cry about things. A lot of us women, that have been through stuff, I notice, we do try to keep face. So, it's just the little network and supporting stuff really. " [Siobhan]

Hearing about the diversity of caregiver's involvement in care and how each patient has different relationships with their family members can help caregivers to be more acceptable towards the possible rejections they may receive from their loved one.
In order to have a positive outlook on their caring role, caregivers emphasized the need for looking after themselves and discouraging feelings of guilt and self-shame "To think you want to support and help but also you are a human being yourself and you've got your own needs to look after. So it's' a balancing act where you look at the risk. " [Helen]

\section{DISCUSSION}

Through a creative process of producing video stories surrounding lived-experiences of SMI we have explored how the design and creation of digital media can support the exchange of information, advice and experiences related to severe mental illness. In doing so, we have highlighted some of the key qualities of health-related information and support that are valued by those affected by SMI. Furthermore, we have highlighted the challenges we faced for portraying privacy sensitive, lived-experiences of a representative sample of patients and caregivers in the severe mental health context. In the following, we offer a set of considerations for future research exploring the development of relatable and empathetic digital content for online provision and support tools.

\section{Caring as a shared experience}

Digital storytelling has been used in the healthcare sector to allow meaningful reflection on the experiences of those affected by chronic health conditions, in terms of training health professionals, increasing patient engagement in organisational change, and assisting patients in making decisions about their health [34, 36, 39, 88]. However, the focus has predominantly been on the experience sharing of patients and less about caregivers' side of the story. Given the impact of chronic health condition on all members of the family in addition to their significant but invisible role in supporting their loved one, very few studies -of those mainly in physical health-have explored sharing experiences of caregivers [48].

The need for caregivers to feel connected through experience, and retain a sense of belonging to other caregivers have been broadly discussed in the literature [10, $51,90]$, indeed this is the main goal of many face to face support groups which bring health communities and their caregivers together. Our participants expressed their desire for positivity to shine through the content. This echoes a finding of [51] where caregivers looked for advice and information conveying positivity and [57] where young dementia caregivers wanted a platform to share and hear positive experiences of dementia. Digital content should retain this positive element whilst portraying a realistic picture of dealing with a particularly challenging domain like mental health.

While the role of caregiving is considered to be similar across all types of caregivers regardless of the condition [51] the stigma associated with mental health can add complexities for sharing personal stories. Healthtalkonline provides an extensive resource of short video stories about experiences of those affected, including caregivers, by a 
variety of health conditions [32]. Although this platform covers a wide range of health conditions, video related to each condition is about 5 minutes long which serves as an introductory reflection to any specific condition. In our study we tried to cover as many aspects of living with SMI as possible. Although we created digital stories for a toolkit aimed to be used by caregivers, we also captured patient's perspectives in our video stories to promote empathy by adding insight into patient's feelings, challenges and needs.

Future designers creating digital tools for caregivers, who struggle to gain access to the caregiver community, particularly around sensitive topics like SMI, could use these shared experiences as a starting point for developing their own understanding of the context of caregiving in SMI or for developing their own scripts to design actor performed experience sharing videos. However, it is worth noting that we had internal validity relating to the relatedness of actor performances because we had involvement of caregivers as advisors throughout the process and the actors had access to the video interviews to base their performances on. Therefore, it is important if this approach is taken to ensure that a rigorous evaluation is conducted to ensure the videos portray the empathy, relatedness and positive experiences that were so important to our participants, and the other caregivers that are represented in the literature.

\section{Bringing characters to life}

We encountered challenges for creating realistic and believable characters; communicating the characters efficiently across the team; and helping actors to capture the lived-experiences. Using persona enabled an efficient way to communicate the character across the team and with actors, as well as helping the analysis team to understand what they are looking for when analyzing the interview data. We aimed to capture a broad range of lived-experiences, characterize distinctive relationships with SMI and to demonstrate how each family member is affected differently by SMI. As noted by Pruitt and Grudin [75] getting the right set of personas is challenging. In our effort we identified different relationships with SMI and interviewed at least one person from each category to gain an understanding of each relationship and the impact of SMI on each family member. We then created a persona for each relationship based on our interviewees and the wider community of people affected by SMI.

It was apparent from our data analysis that our participants valued receiving empathy, relatability, and positive emotion by watching these lived-experience videos. Using actors (reading video scripts), may appear as 'role-played' and 'lifeless'. Collecting rich contextual data in our interviews helped with the development of realistic storylines. To achieve a realistic character in video production stage, our caregiver advisors worked closely with actors to help them understand the lived experiences of people affected by SMI. We used different filmmaking practices e.g. creating the video scripts, helping the actors getting into character, and making sure they were empathic in order to overcome these issues. Hence from an evaluation perspective, we still need to investigate whether the wider audience accessing the REACT toolkit perceived the videos to be realistic and close to their personal experiences. As such, we encourage future researchers wishing to produce lived-experience video stories, to engage enough time with the target audience to successfully project their values in all production stages.

\section{The ownership dilemma}

The project introduced several ethical challenges we did not envision from the beginning. Whilst we had expected that there would be a need to maintain absolute privacy when discussing sensitive topics, we had not considered the fact that there may be issues over the ownership of the stories, when being discussed by a caregiver. Although caregivers shared their perspectives and experiences of certain events, the incidents they described had very much happened to their loved one, and not them. Maintaining privacy and protecting the identity of the patient came across strongly during discussions with our advisors and participants, which led to the eventual use of actors.

Ownership concept is wrongly assumed to be within the context of granting editorial rights and copyright to the storyteller [93] and overlooking the ripple effect of sharing personal information online. Whilst many previous studies have used real participants for the creation of video content (e.g. [33, 95]), and allowed participants to make an informed and considered decision about publishing their story through which the responsibility for disclosure remained with the participant [35], when discussing highly sensitive topics we must consider the privacy of all individuals involved in the story. We need to think well beyond the ethical process of consent and explicitly answer the question of who is being discussed in this story and how they may be effected by the content that could further complicate their personal and professional life.

The notion of engaging with digital stories in sensitive domains can attract negative responses from the online audience and cause harm to the storyteller [93]. Therefore the need for sensitivity when creating and sharing personal stories publicly is highlighted in the literature $[23,33]$. This echoes concerns raised by our participants regarding the impact of being identified through sharing stories as someone affected by SMI. In our study we intended to create stories for a toolkit which is a closed environment for registered users and will not be searchable in the same way as social media platforms are but for example when people are discussing a challenging SMI incident, they might unwittingly discuss identifiable information about their loved one. Created stories should be representative of participants' personal experiences which are often highly personal and unique. For example, one of our participants explained a very challenging crises incident about her brother. At the end of the interview she raised concerns about being identified since the incident was very unique and was 
already being discussed in her small town. This is more challenging in smaller communities where this identification can be highly possible and damaging. Although our toolkit is a secure and closed environment, designers wishing to create digital stories open to the general public need to be mindful of this issue and work closely with people who are affected in different ways with SMI to mitigate the risk of sharing personal information on video stories.

\section{It's an emotional process! The ethical challenges}

Working alongside 'experts by experience' (e.g. those effected by SMI) to gain insight into their lived-experiences throughout the process of creating videos was necessary yet challenging not only in the context of participants' emotional wellbeing but also emotional burden on researchers [21]. While safeguarding around emotional wellbeing of participants is a standard practice in research, researchers' own wellbeing has received less attention in the literature particularly in HCI [61]. In our process of creating videos we also encountered the need for protecting researcher's wellbeing which we were not prepared for. As a researcher, you may feel uncomfortable and emotionally involved hearing these lived-experience stories [89], and conducting such research requires the researcher to be able to distance themselves from the research domain [61]. Whilst researchers vary in relation to the type of support they wish to seek out, journal writing, peer debriefing, taking time out of research, reflection and therapeutic counselling have all been highlighted as preferred techniques to maintain emotional wellbeing in sensitive research $[9,15,17,61,76]$. On request of some participants their interviews were conducted via WebEx. During one of the interviews with a patient suffering from psychosis the participant became very emotional remembering and sharing stories about his own suicidal thoughts, losing his brother to suicide, how his condition affected his family and how his wife has been an amazing support through the years. He became deeply upset and was unable to complete the interview. Since the interview was held over the internet, the researcher found it difficult to assist. This unplanned emotional distress to the participant with psychosis can be triggering and incredibly risky. While our risk mitigation strategy included a follow up email and phone call at a later time, in this incident we needed a faster action plan which was not envisioned in our strategy. Fortunately, this participant was not alone as we intended to interview his wife afterwards. Online tools such as Skype or WebEx can facilitate a space to engage with a wider population and more importantly with hard to reach participants in terms of geographical limitations. While this offered inclusivity makes online tools an emerging space for conducting research, there is limited policy around online care provision and safeguarding. HCI researchers working in sensitive domains need to ensure this type of content is delivered in the context of supportive tools, wherein there are clear details around how to improve one's situation.

\section{CONCLUSION}

In this paper, we have focused on exploring the encounters and opportunities that are facing the use of video medium to capture lived-experiences of those who are 'expert by experience' in the context of SMI. There is a need for relatable, but privacy sensitive media content in online toolkits for health: evidenced by the issues raised in our approach surrounding the consent process and involving people and their stories in creation of 'expert by experience' videos. This type of video content production is a lengthy task, and there are many ethical challenges that must be considered for example involving a representative from the target population throughout the process. Yet to make the videos relatable, we need to ensure the voice of the participants shine through when using actors and that the videos appear realistic.

\section{ACKNOWLEDGMENTS}

The authors would like to thank all our participants for sharing their lived-experience stories in the course of this study. We would also like to thank our actors and everyone within the REACT Group who were involved in developing the storylines. This paper presents independent research commissioned by the National Institute of Health Research (NIHR) under the Health Technology Assessment (HTA) Programme (Grant Reference Number 14/49/34). The views expressed are those of the authors and not necessarily those of the NHS, the NIHR or the Department of Health. The funder played no role in the study design, conduct or interpretation of the data. The corresponding author had full access to all the data in the study and had final responsibility for the decision to submit for publication.

\section{REFERENCES}

1. Alison Andrew, Martin Knapp, Paul R McCrone, Michael Parsonage and Marija Trachtenberg. 2012. Effective interventions in schizophrenia: the economic case.

2. A George Awad and Lakshmi NP Voruganti. 2008. The burden of schizophrenia on caregivers. Pharmacoeconomics, 26 (2). 149-162.

3. AG Awad and LN Voruganti. The burden of schizophrenia on caregivers: a review. Pharmacoeconomics [Internet]. 2008 [cited 2012 Nov 10]; 26 (2): 149-62.

4. Jakob E Bardram, Mads Frost, Károly Szántó, Maria Faurholt-Jepsen, Maj Vinberg and Lars Vedel Kessing. 2013. Designing mobile health technology for bipolar disorder: a field trial of the monarca system. in Proceedings of the SIGCHI conference on human factors in computing systems, ACM, 2627-2636.

5. Pam Briggs, Mark Blythe, John Vines, Stephen Lindsay, Paul Dunphy, James Nicholson, David Green, Jim Kitson, Andrew Monk and Patrick Olivier. 2012. Invisible design: exploring insights and ideas through ambiguous film scenarios. in 
Proceedings of the Designing Interactive Systems Conference, ACM, 534-543.

6. Pamela Briggs, Brad Simpson and Antonella Angeli. 2004. Personalisation and trust: a reciprocal relationship? Designing Personalized user experiences in eCommerce. 39-55.

7. Vicki Bruce. 1996. The role of the face in communication: Implications for videophone design. Interacting with computers, 8 (2). 166-176.

8. Lisa Buckner and Sue Yeandle. 2015. Valuing Carers 2015-The rising value of carers' support. London: Carers UK.

9. Sarah Burns and Chris Bulman. 2003. Reflective practice in nursing: The growth of the professional practitioner. Blackwell Science.

10. Yunan Chen, Victor Ngo and Sun Young Park. 2013. Caring for caregivers: designing for integrality. in Proceedings of the 2013 conference on Computer supported cooperative work, ACM, 91-102.

11. Wai-Tong Chien and Ian Norman. 2009. The effectiveness and active ingredients of mutual support groups for family caregivers of people with psychotic disorders: a literature review. International journal of nursing studies, 46 (12). 1604-1623.

12. Wai Tong Chien and Ka-Fai Wong. 2007. A family psychoeducation group program for Chinese people with schizophrenia in Hong Kong. Psychiatric services, 58 (7). 1003-1006.

13. Rachel Clarke, Peter Wright, Madeline Balaam and John McCarthy. 2013. Digital portraits: photo-sharing after domestic violence. in Proceedings of the SIGCHI conference on Human factors in computing systems, ACM, 2517-2526.

14. Alan Cooper. 2004. The inmates are running the asylum:[Why high-tech products drive us crazy and how to restore the sanity]. Sams Indianapolis, IN, USA:

15. Anne Corden, Roy Sainsbury, Patricia Sloper and Bernard Ward. 2005. Using a model of group psychotherapy to support social research on sensitive topics. International Journal of Social Research Methodology, 8 (2). 151-160.

16. Patrick W Corrigan and Frederick E Miller. 2004. Shame, blame, and contamination: A review of the impact of mental illness stigma on family members. Journal of Mental Health, 13 (6). 537 548.

17. Hilary Davis and Jenny Waycott. 2015. Ethical encounters: HCI research in sensitive and complex settings. in Proceedings of the Annual Meeting of the Australian Special Interest Group for Computer Human Interaction, ACM, 667-669.

18. Hilary Davis, Jenny Waycott and Shou Zhou. 2015. Beyond YouTube: Sharing personal digital stories on a community display. in Proceedings of the Annual Meeting of the Australian Special Interest Group for Computer Human Interaction, ACM, 579-587.

19. John F Deeken, Kathryn L Taylor, Patricia Mangan, K Robin Yabroff and Jane M Ingham. 2003. Care for the caregivers: a review of selfreport instruments developed to measure the burden, needs, and quality of life of informal caregivers. Journal of pain and symptom management, 26 (4). 922-953.

20. Mary Amanda Dew, Jean M Goycoolea, Ronna C Harris, Ann Lee, Rachelle Zomak, Jacqueline Dunbar-Jacob, Armando Rotondi, Bartley P Griffith and Robert L Kormos. 2004. An internetbased intervention to improve psychosocial outcomes in heart transplant recipients and family caregivers: development and evaluation. The Journal of heart and lung transplantation, 23 (6). 745-758.

21. Virginia Dickson-Swift, Erica L James, Sandra Kippen and Pranee Liamputtong. 2007. Doing sensitive research: what challenges do qualitative researchers face? Qualitative research, 7 (3). 327 353.

22. Lori L DuBenske, David H Gustafson, Bret R Shaw and James F Cleary. 2010. Web-based cancer communication and decision making systems: connecting patients, caregivers, and clinicians for improved health outcomes. Medical Decision Making. 0272989X10386382.

23. Fran Edmonds, Richard Chenhall, Michael Arnold, Tania Lewis and Susan Lowish. 2014. Telling our stories: Aboriginal young people in Victoria and digital storytelling. Institute for a BroadbandEnabled Society, Melbourne.

24. Pin Sym Foong, Shengdong Zhao, Felicia Tan and Joseph Jay Williams. 2018. Harvesting Caregiving Knowledge: Design Considerations for Integrating Volunteer Input in Dementia Care. in Proceedings of the 2018 CHI Conference on Human Factors in Computing Systems, ACM, 79.

25. Dennis Owen Frohlich and Anne ZmyslinskiSeelig. 2012. The presence of social support messages on YouTube videos about inflammatory bowel disease and ostomies. Health Communication, 27 (5). 421-428.

26. Jeana H Frost and Michael P Massagli. 2008. Social uses of personal health information within PatientsLikeMe, an online patient community: what can happen when patients have access to one another's data. Journal of medical Internet research, 10 (3).

27. Frederick K Goodwin and Kay Redfield Jamison. 2007. Manic-depressive illness: bipolar disorders and recurrent depression. Oxford University Press. 
28. Kim Goodwin. 2001. Goal-directed methods for great design. ACM.

29. Arild Granerud and Elisabeth Severinsson. 2006. The struggle for social integration in the community-the experiences of people with mental health problems. Journal of Psychiatric and Mental Health Nursing, 13 (3). 288-293.

30. Charles J Greenberg and Lei Wang. 2012. Building health literacy among an urban teenage population by creating online health videos for public and school health curriculum use. Journal of consumer health on the Internet, 16 (2). 135146.

31. Frances Griffiths, Antje Lindenmeyer, John Powell, Pam Lowe and Margaret Thorogood. 2006. Why are health care interventions delivered over the internet? A systematic review of the published literature. Journal of medical Internet research, 8 (2).

32. Health Experiences Research Group. 2010. Researcher's handbook for producing HealthTalkOnline and YouthHealthTalk websites.

33. Aline C Gubrium, Amy L Hill and Sarah Flicker. 2014. A situated practice of ethics for participatory visual and digital methods in public health research and practice: A focus on digital storytelling. American Journal of Public Health, 104 (9). 1606-1614.

34. Carol Haigh and Pip Hardy. 2011. Tell me a story - a conceptual exploration of storytelling in healthcare education. Nurse education today, 31 (4). 408-411.

35. Pip Hardy. 2007. An investigation into the application of the Patient Voices digital stories in healthcare education: quality of learning, policy impact and practice-based value. Avialable at http://www. pilgrimprojects. co. uk/papers/phardymsc. pdf (accessed 18/09/09).

36. Pip Hardy and Tony Sumner. 2018. Cultivating compassion: How digital storytelling is transforming healthcare. Springer.

37. Dave Harley and Geraldine Fitzpatrick. 2009. YouTube and intergenerational communication: the case of Geriatric1927. Universal access in the information society, 8 (1). 5-20.

38. National Institute for Health and Clinical Excellence. 2009. Schizophrenia: Core interventions in the treatment and management of schizophrenia in adults in primary and secondary care. National Institute for Health and Clinical Excellence.

39. A Herxheimer and S Ziebland. 2004. DIPEx: Collecting personal experiences to help other patients and educate professionals. Narrative research in health and illness. London: BMJ Books. 115-131.
40. Tina Hoff, Meredith Mishel and Ian Rowe. 2008. Using new media to make HIV personal: A partnership of MTV and the Kaiser Family Foundation. Cases in Public Health Communication \& Marketing, 2. 190-197.

41. Meg Hourihan. 2002. Taking the-you "out of user: My experience using Personas. Boxes and arrows.

42. Jina Huh, Leslie S Liu, Tina Neogi, Kori Inkpen and Wanda Pratt. 2014. Health vlogs as social support for chronic illness management. $A C M$ Transactions on Computer-Human Interaction (TOCHI), 21 (4). 23.

43. S Jones and S Fox. 2009. The social life of health information. Pew research center, Washington, DC Pew Internet \& American Life Project.

44. Ronald C Kessler, Sergio Aguilar-Gaxiola, Jordi Alonso, Somnath Chatterji, Sing Lee, Johan Ormel, T Bedirhan Üstün and Philip S Wang. 2009. The global burden of mental disorders: an update from the WHO World Mental Health (WMH) surveys. Epidemiology and Psychiatric Sciences, 18 (1). 23-33.

45. Elizabeth Kuipers, Juliana Onwumere and Paul Bebbington. 2010. Cognitive model of caregiving in psychosis. The British Journal of Psychiatry, 196 (4). 259-265.

46. Nicholas D Lane, Mashfiqui Mohammod, Mu Lin, Xiaochao Yang, Hong Lu, Shahid Ali, Afsaneh Doryab, Ethan Berke, Tanzeem Choudhury and Andrew Campbell. 2011. Bewell: A smartphone application to monitor, model and promote wellbeing. in 5th international ICST conference on pervasive computing technologies for healthcare, 23-26.

47. Morton A Lieberman, Andrew Wizlenberg, Mitch Golant and Mariann Di Minno. 2005. The impact of group composition on Internet support groups: Homogeneous versus heterogeneous Parkinson's groups. Group Dynamics: Theory, Research, and Practice, 9 (4). 239.

48. Leslie S Liu, Jina Huh, Tina Neogi, Kori Inkpen and Wanda Pratt. 2013. Health vlogger-viewer interaction in chronic illness management. in Proceedings of the SIGCHI conference on Human factors in computing systems, ACM, 49-58.

49. Fiona Lobban, Adam Postlethwaite, David Glentworth, Vanessa Pinfold, Laura Wainwright, Graham Dunn, Anna Clancy and Gillian Haddock. 2013. A systematic review of randomised controlled trials of interventions reporting outcomes for relatives of people with psychosis. Clinical Psychology Review, 33 (3). 372-382.

50. Fiona Lobban, Heather Robinson, Duncan Appelbe, Johanna Barraclough, Emma Bedson, Lizzie Collinge, Susanna Dodd, Sue Flowers, Mahsa Honary and Sonia Johnson. 2017. Protocol 
for an online randomised controlled trial to evaluate the clinical and cost-effectiveness of a peer-supported self-management intervention for relatives of people with psychosis or bipolar disorder: Relatives Education And Coping Toolkit (REACT). BMJ open, 7 (7). e016965.

51. Kiel Long, Lyndsey L Bakewell, Roisin C McNaney, Konstantina Vasileiou, Mark Atkinson, Manuela Barreto, Julie Barnett, Michael Wilson, Shaun Lawson and John Vines. 2017. Connecting Those That Care: Designing for Transitioning, Talking, Belonging and Escaping. in Proceedings of the 2017 CHI Conference on Human Factors in Computing Systems, ACM, 1339-1351.

52. Benedicte Lowyck, Marc De Hert, E Peeters, M Wampers, P Gilis and Joseph Peuskens. 2004. A study of the family burden of 150 family members of schizophrenic patients. European Psychiatry, 19 (7). 395-401.

53. Lorenza Magliano, Andrea Fiorillo, Corrado De Rosa, Claudio Malangone, Mario Maj and National Mental Health Project Working Group. 2005. Family burden in long-term diseases: a comparative study in schizophrenia vs. physical disorders. Social science \& medicine, 61 (2). 313322.

54. Julie T Marks, Marci K Campbell, Dianne S Ward, Kurt M Ribisl, Barbara M Wildemuth and Michael J Symons. 2006. A comparison of Web and print media for physical activity promotion among adolescent girls. Journal of Adolescent Health, 39 (1). 96-104.

55. Mark Matthews, Stephen Voida, Saeed Abdullah, Gavin Doherty, Tanzeem Choudhury, Sangha Im and Geri Gay. 2015. In situ design for mental illness: Considering the pathology of bipolar disorder in mhealth design. in Proceedings of the 17th International Conference on HumanComputer Interaction with Mobile Devices and Services, ACM, 86-97.

56. Katelyn YA McKenna, Amie S Green and Marci EJ Gleason. 2002. Relationship formation on the Internet: What's the big attraction? Journal of social issues, 58 (1). 9-31.

57. Roisin McNaney, John Vines, Jamie Mercer, Leon Mexter, Daniel Welsh and Tony Young. 2017. DemYouth: Co-Designing and Enacting Tools to Support Young People's Engagement with People with Dementia. in Proceedings of the 2017 CHI Conference on Human Factors in Computing Systems, ACM, 1313-1325.

58. Lauren R Meltzer, Cathy D Meade, Diana B Diaz, Monica S Carrington, Thomas H Brandon, Paul B Jacobsen, Judith C McCaffrey, Eric B Haura and Vani N Simmons. 2016. Development of a Targeted Smoking Relapse-Prevention
Intervention for Cancer Patients. Journal of Cancer Education. 1-8.

59. Philip B Mitchell, Colleen K Loo and Bronwyn M Gould. 2010. Diagnosis and monitoring of bipolar disorder in general practice. Med J Aust, 193 (4 Suppl). S10-S13.

60. Heather Molyneaux, Susan O’Donnell, Kerri Gibson and Janice Singer. 2008. Exploring the gender divide on YouTube: An analysis of the creation and reception of vlogs. American Communication Journal, 10 (2). 1-14.

61. Wendy Moncur. 2013. The emotional wellbeing of researchers: considerations for practice. in Proceedings of the SIGCHI Conference on Human Factors in Computing Systems, ACM, 1883-1890.

62. M. A. Newman, S. Ziebland and K. L. Barker. 2009. Patients' views of a multimedia resource featuring experiences of rheumatoid arthritis: pilot evaluation of www.healthtalkonline.org. Health Informatics Journal, 15 (2). 147-159.

63. Cameron D Norman and Andrea L Yip. 2012. eHealth promotion and social innovation with youth: using social and visual media to engage diverse communities. Studies in health technology and informatics, 172. 54-70.

64. Laurel Northouse, Anna-leila Williams, Barbara Given and Ruth McCorkle. 2012. Psychosocial care for family caregivers of patients with cancer. Journal of Clinical Oncology, 30 (11). 1227-1234.

65. Braden O'Neill, Sue Ziebland, Jose Valderas and Francisco Lupiáñez-Villanueva. 2014. Usergenerated online health content: a survey of Internet users in the United Kingdom. Journal of medical Internet research, 16 (4).

66. Patrick Cheong-Iao Pang, Karin Verspoor, Jon Pearce and Shanton Chang. 2015. Better health explorer: Designing for health information seekers. in Proceedings of the Annual Meeting of the Australian Special Interest Group for Computer Human Interaction, ACM, 588-597.

67. James W Pennebaker and Janel D Seagal. 1999. Forming a story: The health benefits of narrative. Journal of clinical psychology, 55 (10). 12431254.

68. Nicole Amoyal Pensak, Tanisha Joshi, Teresa Simoneau, Kristin Kilbourn, Alaina Carr, Jean Kutner and Mark L Laudenslager. 2017. Development of a Web-Based Intervention for Addressing Distress in Caregivers of Patients Receiving Stem Cell Transplants: Formative Evaluation With Stakeholder Interviews and Focus Groups. JMIR research protocols, 6 (6).

69. Deborah A Perlick, David J Miklowitz, Norma Lopez, James Chou, Carla Kalvin, Victoria Adzhiashvili and Andrew Aronson. 2010. Familyfocused treatment for caregivers of patients with 
bipolar disorder. Bipolar disorders, 12 (6). 627-

637.

70. Deborah Perlick, John F Clarkin, Joanne Sirey, Patrick Raue, Susan Greenfield, Elmer Struening and Robert Rosenheck. 1999. Burden experienced by care-givers of persons with bipolar affective disorder. The British Journal of Psychiatry, 175 (1). 56-62.

71. Tamara Peyton and Erika Poole. 2013. My Mobile Health, My Mobile Life: methods for designing health interventions with adolescents. in $\mathrm{CHI}^{\prime} 13$ Extended Abstracts on Human Factors in Computing Systems, ACM, 481-486.

72. Jenny Ploeg, Maureen Markle-Reid, Ruta Valaitis, Carrie McAiney, Wendy Duggleby, Amy Bartholomew and Diana Sherifali. 2017. WebBased Interventions to Improve Mental Health, General Caregiving Outcomes, and General Health for Informal Caregivers of Adults With Chronic Conditions Living in the Community: Rapid Evidence Review. Journal of Medical Internet Research, 19 (7).

73. David Premack and Guy Woodruff. 1978. Does the chimpanzee have a theory of mind? Behavioral and brain sciences, 1 (4). 515-526.

74. J Pruitt, Holly Jamesen and Tamara Adlin. 2001. Personas, user archetypes, and other user representations in software design. in $U P A$ Workshop.

75. John Pruitt and Jonathan Grudin. 2003. Personas: practice and theory. in Proceedings of the 2003 conference on Designing for user experiences, ACM, 1-15.

76. Kathleen B Rager. 2005. Self-care and the qualitative researcher: When collecting data can break your heart. Educational Researcher, 34 (4). 23-27.

77. M Reinares and E Vieta. 2004. The burden on the family of bipolar patients. Clinical approaches in bipolar disorders, 3 (1). 17-23.

78. Armando J Rotondi, Carol M Anderson, Gretchen L Haas, Shaun M Eack, Michael B Spring, Rohan Ganguli, Christina Newhill and Jason Rosenstock. 2010. Web-based psychoeducational intervention for persons with schizophrenia and their supporters: one-year outcomes. Psychiatric Services, 61 (11). 1099-1105.

79. Jennifer L Scott, Sarah Dawkins, Michael G Quinn, Kristy Sanderson, Kate-Ellen J Elliott, Christine Stirling, Ben Schüz and Andrew Robinson. 2016. Caring for the carer: a systematic review of pure technology-based cognitive behavioral therapy (TB-CBT) interventions for dementia carers. Aging \& mental health, 20 (8). 793-803.

80. Elizabeth Sillence, Pam Briggs, Lesley Fishwick and Peter Harris. 2004. Trust and mistrust of online health sites. in Proceedings of the SIGCHI conference on Human factors in computing systems, ACM, 663-670.

81. Elizabeth Sillence, Pam Briggs, Peter Richard Harris and Lesley Fishwick. 2007. How do patients evaluate and make use of online health information? Social science \& medicine, 64 (9). 1853-1862.

82. Elizabeth Sillence, Pamela Briggs, Lesley Fishwick and Peter Harris. 2005. Guidelines for developing trust in health websites. in Special interest tracks and posters of the 14th international conference on World Wide Web, ACM, 1026-1027.

83. Elizabeth Sillence, Claire Hardy and Pam Briggs. 2013. Why don't we trust health websites that help us help each other?: an analysis of online peer-topeer healthcare. in Proceedings of the 5th Annual ACM Web Science Conference, ACM, 396-404.

84. Gregory C Smith, Nichole Egbert, Mary DellmanJenkins, Kevin Nanna and Patrick A Palmieri.

2012. Reducing depression in stroke survivors and their informal caregivers: a randomized clinical trial of a Web-based intervention. Rehabilitation psychology, 57 (3). 196.

85. Hayeon Song, Yujung Nam, Jessica Gould, W Scott Sanders, Margaret McLaughlin, Janet Fulk, Kathleen A Meeske and Kathleen S Ruccione. 2012. Cancer survivor identity shared in a social media intervention. Journal of Pediatric Oncology Nursing, 29 (2). 80-91.

86. Liz Spencer and Jane Ritchie. 2002. Qualitative data analysis for applied policy research. in Analyzing qualitative data, Routledge, 187-208.

87. Annie Steele, Nancy Maruyama and Igor Galynker. 2010. Psychiatric symptoms in caregivers of patients with bipolar disorder: a review. Journal of affective disorders, 121 (1). 1021.

88. R Stenhouse, J Tait, P Hardy and T Sumner. 2013 Dangling conversations: reflections on the process of creating digital stories during a workshop with people with early-stage dementia. Journal of psychiatric and mental health nursing, 20 (2). 134141.

89. Anja Thieme, Jayne Wallace, Paula Johnson, John McCarthy, Siân Lindley, Peter Wright, Patrick Olivier and Thomas D Meyer. 2013. Design to promote mindfulness practice and sense of self for vulnerable women in secure hospital services. in Proceedings of the SIGCHI Conference on Human Factors in Computing Systems, ACM, 2647-2656.

90. Matthieu Tixier and Myriam Lewkowicz. 2016. Counting on the group: reconciling online and offline social support among older informal caregivers. in Proceedings of the 2016 CHI 
Conference on Human Factors in Computing

Systems, ACM, 3545-3558.

91. Anupriya Tuli, Pushpendra Singh, Mamta Sood, Koushik Sinha Deb, Siddharth Jain, Abhishek Jain, Manan Wason, Rakesh Chadda and Rohit Verma. 2016. Harmony: close knitted mhealth assistance for patients, caregivers and doctors for managing SMIs. in Proceedings of the 2016 ACM International Joint Conference on Pervasive and Ubiquitous Computing: Adjunct, ACM, 11441152.

92. John Vines, Peter C Wright, David Silver, Maggie Winchcombe and Patrick Olivier. 2015. Authenticity, Relatability and Collaborative Approaches to Sharing Knowledge about Assistive Living Technology. in Proceedings of the 18th ACM Conference on Computer Supported Cooperative Work \& Social Computing, ACM, 8294.

93. Sonja Vivienne. 2014. Mediating Influences: Problematising facilitated digital selfrepresentation. Conjunctions. Transdisciplinary Journal of Cultural Participation, 1 (1). 1-25.

94. Marina B Wasilewski, Jennifer N Stinson and Jill I Cameron. 2017. Web-based health interventions for family caregivers of elderly individuals: A Scoping Review. International Journal of Medical Informatics.

95. Jenny Waycott, Frank Vetere, Sonja Pedell, Lars Kulik, Elizabeth Ozanne, Alan Gruner and John Downs. 2013. Older adults as digital content producers. in Proceedings of the SIGCHI Conference on Human Factors in Computing Systems, ACM, 39-48.

96. Daniel Welsh, Kellie Morrissey, Sarah Foley, Roisin McNaney, Christos Salis, John McCarthy and John Vines. 2018. Ticket to Talk: Supporting Conversation between Young People and People with Dementia through Digital Media. in Proceedings of the 2018 CHI Conference on Human Factors in Computing Systems, ACM, 375.

97. Celia E Wills. 2003. Caregivers experienced 6 phases in coping over time with severe and persistent mental illness in a family member. Evidence-based nursing, 6 (3). 94.

98. Kevin B Wright, Sally B Bell, Kevin B Wright and Sally B Bell. 2003. Health-related support groups on the Internet: Linking empirical findings to social support and computer-mediated communication theory. Journal of Health Psychology, 8 (1). 39-54.

99. Amina Yesufu-Udechuku, Bronwyn Harrison, Evan Mayo-Wilson, Norman Young, Peter Woodhams, David Shiers, Elizabeth Kuipers and Tim Kendall. 2015. Interventions to improve the experience of caring for people with severe mental illness: systematic review and meta-analysis. The British Journal of Psychiatry, 206 (4). 268-274.

100. Sue Ziebland, Alison Chapple, Carol Dumelow, Julie Evans, Suman Prinjha and Linda Rozmovits. 2004. How the internet affects patients' experience of cancer: a qualitative study. Bmj, 328 (7439). 564. 